\title{
MUDANÇAS IDENTIFICADAS PELO ALUNO DE ENFERMAGEM, RESULTANTES DA VIVÊNCIA EM UMA ABORDAGEM CENTRADA NA PESSOA*
}

\author{
Margareth Angelo** \\ Regina Szylit Bousso*** \\ Marilene Alice da C. Santos**** \\ Ana Lucia de Moraes Horta***** \\ Marcia A.M. Caldas*****
}

ANGELO, M.; BOUSSO, R.S.; SANTOS, M.A. da C.; HORTA, A.L.; CALDAS, M.A.M. Mudanças identificadas pelo aluno de enfermagem, resultantes da vivência em uma abordagem centrada na pessoa. Rev. Esc. Enf. USP, São Paulo, 23(3):363-368, dez. 1989.

A vivência das autoras no ensino de enfermagem pediátrica na EEUSP, tem sido direcionada pela crença de que uma das mais importantes condiçōes que facilitam a aprendizagem, é a qualidade de atitudes do relacionamento interpessoal entre professores e alunos.

Neste trabalho, apresentam a analise das informaçōes contidas em autoavaliaçóes de alunos, referentes a mudanças pessoais ocorridas como resultado desse relacionamento durante o curso em 1985.

Os resultados da analise mostraram que além da aquisição de conhecimentos espectficos de enfermagem pediátrica, os alunos identificaram variados aspectos de desenvolvimento pessoal.

UNITERMOS: Ensino de enfermagem. Aprendizagem. Relaçôes interpessoais.

\section{INTRODUÇĀO}

ROGERS 5 acredita ser o objetivo educacional a facilitação do processo de mudança e aprendizagem e que o homem educado é aquele que aprendeu a mudar, a se adaptar, que percebe que nenhum conhecimento é seguro e que só o processo de buscar conhecimento oferece alguma fonte de segurança.

* Trabalho apresentado no XVII Encontro de Enfermeiros Pediátricos, Ribeirāo Preto, 1986.

** Professor Ássistente da Disciplina Enfermagem Pediátria do Departamento de Enfermagem Materno-Infantil e Psiquiátrica da Escola de Enfermagem da Universidade de São Paulo.

*** Auxiliar de Ensino da Disciplina Enfermagem Pediátrica do Departamento de Enfermagem Materno-Infantil e Psiquiátrica da Escola de Enfermagem da Universidade de São Paulo.

**** Enfermeira, Docente do Colégio Técnico de Limeira - UNICAMP.

***** Enfermeira, aluna do curso de Pós-Graduação, nível Mestrado, da Escola de Enfermagem da USP, 1988. 
ROGERS 4 entende por aprendizagem significativa, uma aprendizagem que é mais do que uma acumulação de fatos; é uma aprendizagem que provoca uma modificação, quer seja no comportamento do indivíduo, na orientação da ação futura que escolhe, ou nas suas atitudes e na sua personalidade.

Baseadas neste postulado, temos nos empenhado em facilitar ao aluno de enfermagem, a vivência de experiências significativas em enfermagem pediátrica.

É uma aprendizagem dessa natureza que pretendemos facilitar em nossa disciplina, acreditando que o aluno só aprende significativamente, quando o objeto de estudo está de acordo com seus objetivos individuais, ou seja, quando the interessa pessoalmente. Nessa perspectiva, a questão que a Abordagem Centrada na Pessoa nos propōe a cada instante é precisamente, a de liberdade do outro e a de seu crescimento, tendo como componente básico a confiança.

$O$ foco principal do ensino centrado no estudante não é a habilidade didática do professor, o uso de meios audiovisuais, as aulas expositivas, a riqueza bibliográfica, embora possam constituir recursos importantes, mas um certo tipo de relacionamento entre professor e aluno.

Segundo ROGERS 5 , a facilitaçāo da aprendizagem significativa repousa em certas qualidades de atitude que existem no relacionamento pessoal entre o facilitador $\mathrm{e} o$ estudante.

De acordo com ROGERS 5 as atitudes que facilitam a aprendizagem são:

\section{- A autenticidade do facilitador}

É a capacidade de viver no relacionamento com os alunos como pessoa real e não como "personagem", ou seja, um indivíduo exercendo o papel de professor. Quando o professor é uma pessoa real, que conhece e vive seus sentimentos e é capaz de comunicá-los, se for apropriado, ele tem muito mais probabilidade de ser eficiente, porque os alunos crescem em contato com alguém que está sendo ele mesmo, que não está se negando, apresentando uma máscara ou fachada.

\section{- Apreço, aceitação, confiança}

É uma aceitação do aluno, como sendo uma pessoa separada, que tem valor por si mesmo, e que é fundamentalmente digna de confiança. É a capacidade de ter carinho e de aceitar o aluno como ser humano imperfeito, com muitos sentimentos e potencialidade, capazes de perturbar e promover a aprendizagem.

\section{- Compreensão empática}

Quando o professor tem a capacidade de compreender internamente as reaçōes do estudante, tem uma consciência sensível da maneira pela qual o processo de educação e aprendizagem se apresenta ao mesmo então, novamente, aumentam as probabilidades de uma aprendizagem significativa. Os alunos sentem-se profundamente valorizados quando não avaliados ou julgados, mas compreendidos, do seu próprio ponto de vista, não o do professor. 
Em nossa experiência com alunos, temos nos empenhado e acreditamos que temos conseguido reagir de maneira autêntica, não avaliadora, aceitadora e empática aos sentimentos demonstrados e verbalizados por eles. Esta porém, é uma opinião parcial do clima por nós oferecido durante a disciplina enfermagem pediátria. É necessário conhecer também, a percepção dos alunos. Não basta que estas atitudes existam no professor. É necessário que tenham sido comunicadas aos alunos. Dessa forma, procuramos obter elementos que nos permitissem perceber se os alunos realmente experimentavam essas atitudes.

Segundo ROGERS 4 quando as atitudes existem, ocorre inevitavelmente um processo de mudança no aluno.

Decidimos então recorrer às informações contidas no impresso de auto-avaliação final, utilizado pela disciplina, onde o aluno registra a avaliação de seu próprio desempenho e progresso no curso ${ }^{3}$.

Dentre as questões contidas no impresso, selecionamos aquela que nos dava informaçōes sobre os possíveis efeitos da disciplina enfermagem pediátrica sobre os alunos, uma vez que o desenvolvimento das potencialidades dos alunos estaria diretamente relacionado à qualidade do clima vivenciado por eles.

A questão escolhida foi:

- Que mudanças você identifica em sua pessoa, como resultado destas oito semanas de curso?

Selecionamos as auto-avaliações dos alunos que cursaram a disciplina em 1985.

\section{MUDANÇAS IDENTIFICADAS PELOS ALUNOS}

Cursaram a disciplina Enfermagem Pediátrica I em 1985, um total de 74 alunos. Foram utilizadas as respostas de 65 impressos, sendo que os 9 restantes por conterem respostas cujo conteúdo não se relacionava à questão, não foram incluídos.

$\mathrm{Na}$ análise do conteúdo das respostas, procuramos identificar dados que caracterizassem os efeitos percebidos pelos alunos em decorrência do curso, não considerando aquelas informaçōes não pertinentes à pergunta.

As mudanças referidas foram listadas e interpretadas segundo sua idéia principal, que deram origem a 4 categorias.

1. Crescimento pessoal.

2. Atitudes que facilitam o relacionamento interpessoal.

3. Conhecimentos específicos de Enfermagem Pediátrica.

4. Reflexões quanto à profissão. 
Para as 2 primeiras categorias, foi necessário utilizar sub-categorias, de modo a explicar melhor em que consistiam, na experiência do aluno.

A seguir passaremos a apresentar cada categoria, utilizando algumas respostas dos alunos, de modo a ilustrar nossa compreensão da idéia apresentada.

Em relação a Crescimento Pessoal, as referências indicaram mudanças quanto a:

\section{- AUTO-CONHECIMENTO:}

- "Refleti sobre coisas em minha vida, mas não imaginava que meu espaço era tão pequeno."

- "Consegui me perceber: enxergar como eu sou."

- AUTO-ACEITAÇÃO:

- "Estou mais aberta, mais posicionada e gostando mais de mim, fazendo novas amizades."

- "Aprendi a me conhecer melhor e tentar trabalhar comigo mesma para resolução dos meus problemas."

- AUTO-CONFIANÇA:

- "Tenho coragem de dizer as coisas que acredito."

- "Senti-me segura em mudar de objetivos, quando novas motivações surgiram."

Dentre as atitudes que facilitam o relacionamento interpessoal, destacam-se:

- INTERESSE:

- "Passei a suportar um pouco mais o silêncio e dar oportunidade para outra pessoa falar."

- "Mudou minha noção de grupo, passei a me preocupar com as pessoas do grupo."

- COMPREENSĀO:

- "Tento compreender as atitudes da criança e ajudá-la."

- "Compreendo melhor os sentimentos dos outros."

- CONFIANÇA:

- "Acredito mais nas pessoas."

- "Permito que outras pessoas se aproximem mais."

Em Conhecimentos Espectficos de Enfermagem Pediátrica, aparecem citações como:

- "Passei a identificar problemas no comportamento de crianças hospitalizadas." 
- "Adquiri necessidade de conhecer mais profundamente a criança como ser integral."

Para Reflexōes quanto à profissão, os alunos utilizam-se de referências como:

- "Ajudou a pensar o que é ser uma enfermeira."

- "Senti e vivi a importância do envolvimento pessoal e profissional para a assistência da criança."

\section{DISCUSSĀo}

A partir desta organização das informações dos alunos, pudemos observar que as mudanças referidas em maior freqüência dizem respeito à crescimento pessoal e desenvolvimento de atitudes que facilitam o relacionamento interpessoal.

Estes resultados significam para nós uma confirmação de que nosso empenho em criar um clima que favoreça aprendizagem e mudança, está sendo experimentado pelos alunos. Com isso, sentimo-nos cada vez mais motivadas a melhorar como facilitadoras, porque acreditamos num ensino que se traduza em desenvolvimento pessoal tanto para o professor como para o aluno.

BURGESS $^{1}$ refere que todas as habilidades e técnicas adquiridas por um estudante num programa de enfermagem, são internalizados a um grau compatível ao auto-conceito do aprendiz, suas habilidades e disponibilidades para assimilalas. A mesma autora indica também, que os níveis de habilidades manifestados pelo estudante, podem ser vistos como evidências de seu crescimento pessoal.

Segundo EYRES ${ }^{2}$, quanto mais você tem experiência como pessoa dentro das enfermarias e na vida privada, maior progresso você faz em direção à verdadeira prática de enfermagem; quanto mais você viver e aprender sobre si mesmo, tanto mais você avança em direção à verdadeira enfermagem.

As idéias destas duas autoras, ressaltam a necessidade de haver um espaço para o crescimento pessoal na formação do enfermeiro.

Acreditamos que deva haver um lugar para a aprendizagem pela pessoa inteira, com seus sentimentos e idéias integradas. Os programas deveriam se preocupar mais com o desenvolvimento da pessoa como um todo, do que apenas com o treinamento da pessoa em diversas habilidades, e o acumulado de informaçōes.

Acreditamos ainda, que independente da metodologia utilizada pelo professor, efeitos pessoais estão acontecendo aos alunos, durante todo o período de um curso. $\mathrm{O}$ professor deve portanto tentar identificar, além dos conhecimentos adquiridos, que outros resultados seu curso está provocando nos alunos.

Gostaríamos de salientar que a aprendizagem pela pessoa inteira, contém elementos cognitivos, mas certamente possui também elementos de sentimentos 
(curiosidade, vibração, paixão) e, elementos vivenciais (autodisciplina, prudência, autoconfiança).

Nossa vivência como facilitadoras tem nos mostrado aspectos importantes do desenvolvimento pessoal. Temos visto que o aluno freqüentemente reproduz aquilo que vive, e parece que isto é mais forte do que o que é ouvido ou lido. Assim, se ele passa pela experiência de ser compreendido, procura se esforçar para compreender também.

Nesse trabalho, procuramos salientar a importância da confiança no ser humano e de certas atitudes para com os estudantes.

Nossa experiência nos dá elementos para acreditarmos que as atitudes e a confiança não surgem repentinamente no professor, mas são desenvolvidas através da ação baseada em hipóteses. Por tudo isso, concordamos com a afirmação de ROGERS ${ }^{5}$ de que é somente arriscando-se por esses novos caminhos que o professor pode descobrir, por si próprio, se eles são ou não eficientes, se são ou não adequados para ele.

ANGELO, M.; BOUSSO, R.S.; SANTOS, M.A. de C.; HORTA, A.L.; CALDAS, M.A.M. Changes noted by nursing studentes, as a result of a personcentered approach. Rev. Esc. Enf. USP, São Paulo, 23(3):363-368, dez. 1989.

The autors' experience in pediatric nursing teaching, has been directed by the belief that the most important condition that facilitates learnig is the quality off attitudes in interpersonal relationship between teacher-student. The authors analyse the information of 65 students self-evaluation related to personal changes as a result of a student-centered pediatric nursing course. The results show that besides specific knowledge on pediatric nursing, the students notice a great deal of individual development.

UNITERMS: Nursing education. Learning. Student - teacher relations.

\section{REFERÊNCIAS BIBLIOGRÁFICAS}

1 BURGESS, G. The personal development of the nursing student as a conceptual framework. Nurs. Forum, Hillsdale, 17(1): 96-102, 1978.

2 EYRES, P. The role of the nurse in family-centered nursing care. Nurs. Clin. North Am., Philadelphia, 7(1): 27-39, Mar. 1972.

3 NEIRA HUERTA, E. de P.; ANGELO, M.; RIBEIRO, M.O.; HORTA, A.L. de M. O curso de Enfermagem Pediátrica I na Escola de Enfermagem da USP. Rev. Esc. Enf. USP, São Paulo, 19(3): 247-62, dez. 1985 .

4 ROGERS, C.R. Aprendizagem significativa na terapia e na educação. In pessoa. São Paulo, Martins Fontes, 1977. cap. 12. p. 257-73.

5 - O relacionamento interpessoal na facilitaçāo da aprendizagem. In:-_L. Liberdade de aprender em nossa década. 2. ed. Porto Alegre, Artes Médicas, 1986 . cap. 7 . p. 125-42.

Recebido em 03/10/88 